\section{Diabetic vitreopapillary traction and macular oedema}

M Karatas' ${ }^{1}$, JA Ramirez ${ }^{1}$ and A Ophir ${ }^{1,2}$

Keywords: vitreopapillary traction; diabetic macular oedema; optical coherence tomography

\section{Introduction}

Vitreopapillary traction has been the focus of attention in eyes with $^{1,2}$ or without ${ }^{3-5}$ diabetic retinopathy. Diagnosis of the optic nerve head $(\mathrm{ONH})$ traction was based on clinical examination and/or ocular ultrasonography. ${ }^{1-5}$ It may result from either a contracted fibrocellular vitreal membrane or an incomplete detached posterior hyaloid. It has been suggested that vitreopapillary traction may damage the anterior optic nerve, and whereas the effect appears to be reversible, in the long term it might lead to irreversible optic nerve atrophy. ${ }^{2}$ Based on the surgical outcome in diabetic eyes, early diagnosis of vitreopapillary traction followed by early vitrectomy could improve visual acuity and visual-evoked potentials and prevent progressive optic atrophy. ${ }^{2}$

Diffuse diabetic macular oedema (DME) has been found to be associated with high levels of cytokines such as vascular endothelial growth factor in the vitreous, that could affect the tight junctions of both the blood-retinal barrier as well as the retinal pigment epithelial cells. ${ }^{6}$ Increased levels of angiotensin II in the vitreous, and of interleukin- 6 and vascular endothelial growth factor in the aqueous humour and plasma, have also been associated with DME.,8 The Early Treatment Diabetic Retinopathy Study Research Group showed that, in eyes with DME, focal laser photocoagulation reduces the risk of moderate visual loss by $50 \%$ or more, decreases the frequency of persistent macular oedema, and increases the chance for improvement in best-corrected visual acuity (BCVA). However, 15\% of eyes experienced moderate visual loss after 3 years of followup 
despite focal laser photocoagulation. ${ }^{9}$ Lee and Olk $^{10}$ report that gridpattern laser photocoagulation for diffuse DME stabilized visual acuity in $61 \%$ of diabetic eyes. Visual acuity decreased by three or more lines in $14.6 \%$ of the eyes in their series. In a continuous search (for decades) for treatments that lead to reduction of extravasation from leaking blood vessels, Jonas $e t a^{11}$ made a report on 26 eyes of 20 patients with diffuse DME, some of whom following failed laser treatment, who were treated with intravitreal administration of $25 \mathrm{mg}$ triamcinolone acetonide. ${ }^{11}$ After a relatively short follow-up (6.6 \pm 6.1 months; minimum -1 month), visual acuity of $19 \%$ of the eyes did not improve. In another study, 4-mg intravitreal triamcinolone acetonide was administered into 16 eyes with DME unresponsive to laser treatment. ${ }^{12}$ In the latter study, pretreatment optical coherence tomography (OCT) examination ruled out vitreomacular traction. After 3 months, the mean central macular thickness decreased by $57.5 \%$, as measured with the OCT. However, this still remained above the normal macular thickness. Furthermore, out of eight eyes that completed 6 months of follow-up, reinjection of triamcinolone acetonide was required in three of them, because of recurrence of macular oedema.

Diffuse DME may be associated with vitreomacular traction. Massin $e a l^{13}$ report that vitrectomy is beneficial only in eyes in which the diffuse DME is combined with vitreomacular traction by a taut posterior hyaloid..$^{13}$ In their study, retinal thickness returned to normal levels in two of the seven operated eyes but remained slightly increased in five, with persistent intraretinal cysts. In another study on diffuse DME associated with taut posterior hyaloid unresponsive to laser treatment, in which the premacular posterior hyaloid was attached, vitrectomy with removal of the posterior hyaloid was beneficial in some cases. ${ }^{14}$ Kaiser $e t ~ a l^{15}$ reported on nine patients who had thickened, taut posterior hyaloid, with no posterior vitreous detachment. Eight of the nine eyes had posterior hyaloid traction of the macula associated with a shallow macular traction detachment. ${ }^{15} \mathrm{In}$ contrast, other researchers suggest that vitrectomy is beneficial for DME even when the latter is not combined with macular traction, ${ }^{16,17}$ and that it is also beneficial when the posterior hyaloid is already detached from the posterior pole. ${ }^{18}$

Optical coherence tomography (OCT) may perform micron resolution cross-sectional imaging in biological tissues. ${ }^{19,20}$ OCT sections taken through different radial planes, each passing through the ONH (Figure 1) and the macular area, can be used to assess the profile of both. The purpose of this study was to describe an association between sole optic disc traction and DME, which was unresponsive to laser treatment(s).

\section{Methods}

We retrospectively reviewed all cases with diabetic macular oedema that attended our clinic at the Hillel-Yaffe Medical Center, Hadera, between September 2001 and November 2003. The patients had undergone ophthalmic history and examination, colour photography and fluorescein angiography. Ten nonvitrectomized eyes of seven patients with diabetic retinopathy, that were found clinically and/or by OCT to have vitreopapillary traction, were included in the analysis. Eyes with additional traction of the posterior pole, for example, vitreo-macular traction, were excluded from the analysis.

Each eye underwent OCT examination of the posterior pole. The OCT examination (Carl Zeiss Meditec, Dublin, CA, USA) initially included six radial lines (4-mm length each) centred at the optic disc and six others (6-mm length each) centred at the macula. A horizontal scan between the macula and $\mathrm{ONH}$ was performed to evaluate the papillomacular area. An OCT diagnosis of

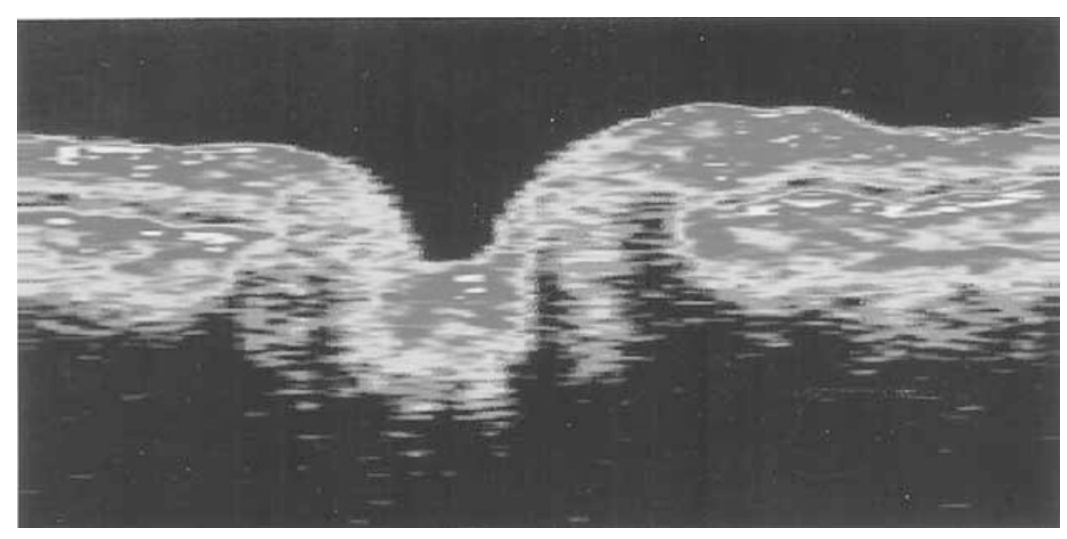

Figure 1 OCT appearance of a normal ONH. 
vitreopapillary elevation and traction was based on the appearance of the $\mathrm{ONH}$ elevation above the retinal surface associated with vitreous traction bands at the disc (Figure 2). Ultrasonography was carried out in five eyes (four patients) to evaluate the connection between the vitreopapillary traction membrane and the retinal periphery. The main outcome measures were the appearance of the $\mathrm{ONH}$, macular configuration and thickness, and vitreous traction bands as detected by the OCT. The approval of Ethics Committee was not required for this study.

\section{Results}

In 10 eyes of the seven diabetic patients, aged 47-79 years (mean 62 \pm 11 ), who were referred to our outpatient clinic for evaluation of macular oedema, elevation of the $\mathrm{ONH}$ was suspected during biomicroscopy in each. An OCT examination of the 10 eyes confirmed traction and elevation of the $\mathrm{ONH}$ towards the vitreous compartment by vitreopapillary membranes (Table 1 ). Of the 10 eyes, nine had previously undergone argon laser photocoagulation. In one eye of each of the seven patients it was the sole traction, whereas in the fellow eyes of three of the patients vitreomacular traction was evident as well (Table 1).

In the seven eyes with only vitreopapillary traction, BCVA ranged from 20/60 to hand movements (Table 1). One eye was pseudophakic (No. 2), and in two eyes cataracts $(+2)$ were present. Three proliferative diabetic retinopathy (PDR) eyes underwent prior pan retinal photocoagulation (PRP). These three eyes and three other eyes with nonproliferative diabetic retinopathy (NPDR) were previously treated for macular oedema. Two PDR eyes and two NPDR eyes underwent macular grid treatment for diffuse DME, while one PDR eye and one NPDR eye were treated focally for focal DME (Table 1). The remaining eye (No. 4),

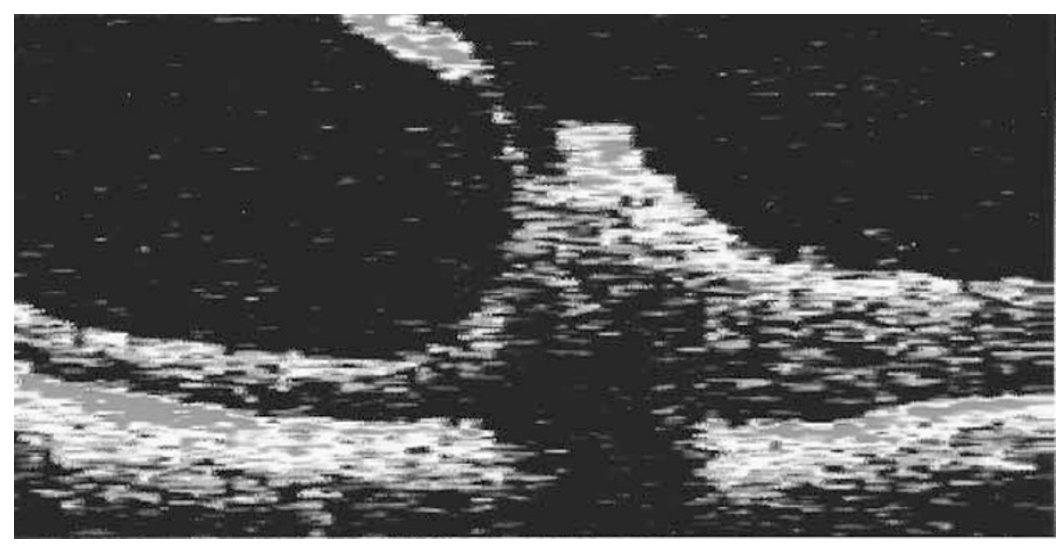

Figure 2 Patient 1. OCT demonstrates nasal traction of the ONH by the posterior hyaloid. Diffuse macula oedema is apparent, having its maximal thickness at the papillomacular bundle site adjacent to the ONH.

Table 1 Demographic data and OCT findings in diabetic patients with vitreopapillary traction

\begin{tabular}{|c|c|c|c|c|c|c|c|c|}
\hline Eye no. & $\begin{array}{c}\text { Age } \\
\text { (years)/gender }\end{array}$ & $\begin{array}{l}\text { Other } \\
\text { diseases }\end{array}$ & $\begin{array}{l}\text { Retinopathy } \\
\text { type }\end{array}$ & $\begin{array}{l}\text { Previous laser } \\
\text { treatment }\end{array}$ & $\begin{array}{l}\text { Serous } \\
R D\end{array}$ & $\begin{array}{l}\text { Macular } \\
\text { edema }\end{array}$ & $B C V A$ & Comments \\
\hline 1 & $79 / \mathrm{M}$ & HT; IHD & PDR & PRP; mac. grid & NO & Diffuse & $20 / 200$ & Cat. +2 \\
\hline 2 & $61 / \mathrm{F}$ & $\begin{array}{l}\text { HT; } \\
\text { glaucoma }\end{array}$ & PDR & PRP; mac. grid & PMB & Diffuse & $20 / 60$ & $\begin{array}{l}\text { Following combined } \\
\text { ECCE + trabeculectomy }\end{array}$ \\
\hline 3 (LE) & $66 / \mathrm{M}$ & $\begin{array}{l}\text { HT; } \\
\text { renal fail }\end{array}$ & NPDR & Macular grid & NO & Diffuse & $20 / 80$ & $\begin{array}{l}\text { Cat. }+2 ; \mathrm{RE} \text { - disc and macular } \\
\text { traction;m. oedema;PMB } \\
\text { detachment }\end{array}$ \\
\hline 4 & $47 / \mathrm{F}$ & No & PDR & $\mathrm{NO}$ & Peripapillary & Diffuse & $\mathrm{FC}-2 \mathrm{~m}$ & \\
\hline 5 (LE) & $61 / \mathrm{F}$ & No & NPDR & Macula - focal & $\mathrm{NO}$ & Diffuse & $20 / 140$ & $\begin{array}{l}\text { RE-disc and macular traction; } \\
\text { diffuse macular oedema }\end{array}$ \\
\hline 6 (LE) & $68 / \mathrm{M}$ & No & PDR & PRP; mac.-focal & $\mathrm{NO}$ & Diffuse & $\mathrm{HM}$ & $\begin{array}{l}\text { RE_-disc and macular traction; } \\
\text { diffuse macular oedema }\end{array}$ \\
\hline 7 & $52 / \mathrm{M}$ & No & NPDR & Macular grid & $\mathrm{NO}$ & Diffuse & $20 / 60$ & \\
\hline
\end{tabular}

$\mathrm{OCT}=$ optical coherence tomography; $\mathrm{LE}=$ left eye $\mathrm{M}=$ male; $\mathrm{F}=$ female; $\mathrm{PRP}=$ panretinal photocoagulation; mac. = macular; $\mathrm{PMB}=$ papillomacular bundle; $\mathrm{RD}=$ retinal detachment; $\mathrm{BCVA}=$ best-corrected visual acuity; $\mathrm{HT}=$ systemic hypertension; $\mathrm{IHD}=$ ischeamic heart disease; $\mathrm{PDR}=$ proliferative diabetic retinopathy; $\mathrm{NPDR}=$ nonproliferative diabetic retinopathy; cat. $=$ cataract; $\mathrm{FC}=$ finger counts; $\mathrm{m}=$ meters; $\mathrm{HM}=$ hand movements. 
with neovascularization at the disc, was not previously treated by argon laser. Vitreous traction was more evident nasally in one eye (No. 1, Figure 2), whereas in the six other eyes it demonstrated double or more, stranded membranes in various locations at the disc, retracting the $\mathrm{ONH}$ into the vitreous compartment (Figure 3).

In each of the seven eyes with sole vitreopapillary traction, diffuse DME (Figure 2) was found using OCT. Mean foveal thickness was $396 \pm 144 \mu \mathrm{m}$ (range, 211-560 $\mu \mathrm{m}$ ). Maximal thickness was detected at the papillomacular bundle site adjacent to the elevated $\mathrm{ONH}$ (Figures 2 and 3(b)) in three eyes, and at the macular site (Figure 4) in the other four eyes. In two eyes (Nos. 2 and 4; Figure 3(a)) a parapapillary hyporeflection space was noted between the retina and retinal pigment epithelium, corresponding to a shallow serous retinal detachment, though without macular detachment. In three patients, their fellow eyes presented with vitreopapillary as well as vitreo-macular traction. Diffuse macular oedema was evident in each (Table 1).

Ultrasonography was performed in five eyes of four patients (Nos. 1-4, bilaterally in patient 3), and demonstrated in each a dense stalk at the prepapillary site. In each, relatively thick vitreal bands were adherent to the stalk. These bands became thinner towards the periphery in four eyes or remained dense throughout their length up to the retinal periphery in the remaining eye. In each, these membranes corresponded to an incompletely detached posterior hyaloid (Figure 5).

\section{Discussion}

Diffuse macular oedema unresponsive to laser treatment was found to be associated with vitreopapillary traction in some eyes with PDR or NPDR. Parapapillary serous retinal detachment was detected in two eyes as well. Two variants in the contour of the diffuse oedema could be

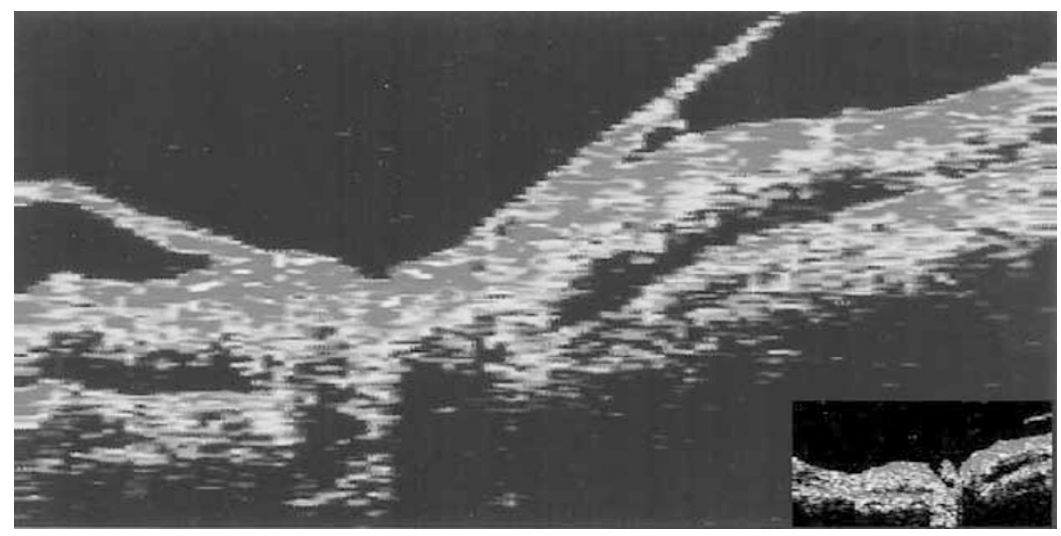

Figure 3 Patient 4. Traction of the ONH by a dense posterior hyaloid, is mainly apparent in a superior-inferior oblique direction, associated with peripapillary serous retinal detachment. The temporal retina, including the macula, is oedematous, being maximal at the papillomacular bundle site adjacent to the $\mathrm{ONH}$ (inset).

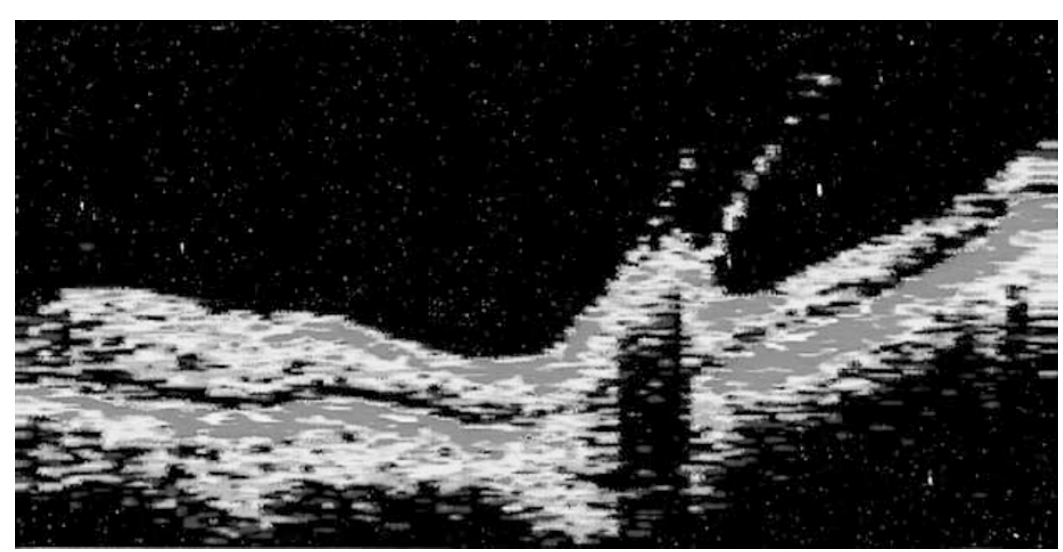

Figure 4 Patient 7. OCT demonstrates traction of the ONH. Diffuse macular oedema is evident, with maximal thickness at the central macular site. 


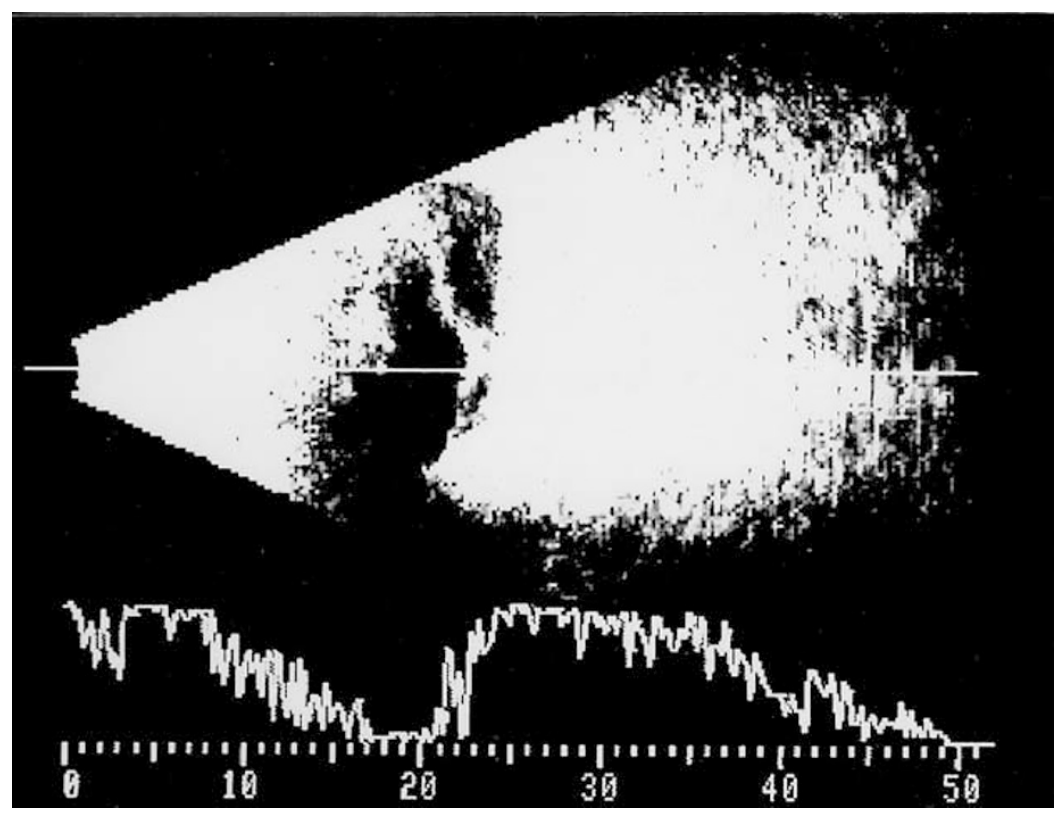

Figure 5 Ultrasonography shows a dense stalk in front of the disc. Echoes corresponding to incompletely detached posterior hyaloid are relatively dense throughout their length from the stalk to the retinal periphery.

recognized, one with its maximum thickness in proximity to the elevated $\mathrm{ONH}$ and the other at the foveal site.

Ultrasound examinations in five eyes suggest that the traction bands were actually the incompletely detached and thickened posterior hyaloid, which were adherent to the $\mathrm{ONH}$ in each. The thickened posterior hyaloid could be the result of encroachment and growth of a peripapillary fibrous tissue over it. Contraction of that tissue could probably result in optic disc traction and inward elevation. In this regard, Foos ${ }^{21}$ postulated that posterior detachment of the vitreous begins in the macular region superiorly and continues nasally towards the ONH. Uchino et $a l^{22}$ in a study of 209 healthy eyes using OCT, report that posterior vitreous detachment initially occurs at the perifovea, extending its range slowly for years, while vitreopapillary adhesion is the last to separate. ${ }^{22}$

In our study, six of seven eyes underwent laser treatments prior to the current diagnosis of vitreopapillary traction. It is possible that vitreopapillary traction existed prior to the laser treatment(s), either PRP and/or macular grid, although its incident following the laser treatment(s) cannot be ruled out. Diffuse macular oedema was found in each, with mean foveal thickness of $396 \pm 144 \mu \mathrm{m}$, whereas in normal, nondiabetic eyes it ranges between $161.9 \pm 12.9^{23}$ and $153 \pm 15 \mu \mathrm{m} .{ }^{24}$ Studies report partial or short-term resolution of diffuse DME following laser treatment or intravitreal triamcinolone acetonide administration. ${ }^{10-12}$ In several studies, vitrectomy was found beneficial for
DME even when the latter is not combined with macular traction. ${ }^{14-18}$ If additional data prove a cause-and-effect association between vitreopapillary traction and diffuse DME in some eyes, it is possible that in the aforementioned studies, some of these cases could have been associated with vitreopapillary traction, a phenomenon that does not seem rare. ${ }^{2}$

Furthermore, vitrectomy might treat existing peripapillary detached retina and its sequelae. It has been suggested that surgery for vitreopapillary traction should be performed meticulously since the removal of the adherent peripapillary membranes or posterior vitreous may be accompanied by an inadvertent excision of axons that may further compromise visual acuity or visual field. ${ }^{25}$

Kroll et al (1999) describe 17 patients with PDR, in whom disc elevation was clinically evident in one eye of each. Eyes with macular oedema were excluded from the study, and traction of the optic disc was thus described only on its nasal side, associated with $\mathrm{ONH}$ pallor and reduced visual acuity. The surgery improved BCVA and visual-evoked potentials in most eyes. The authors suggest that vitreopapillary traction may damage the anterior optic nerve via decreased axoplasmic flow in the optic nerve fibres and/or mechanical reduction of perfusion in the posterior ciliary arteries. They add that the effects of each mechanism appear to be reversible, but in the long term might lead to irreversible optic nerve atrophy. ${ }^{2}$ In our series, vitreopapillary traction at various sites of the ONH is presented. Wisotsky et al (1998) 
present two diabetic patients with vitreopapillary traction in one eye each, based on ocular examination and ultrasonography. The first patient had NPDR, whereas the second did not show signs of diabetic retinopathy. In each of the two eyes, posterior vitreous was incompletely detached, adherent only to the ONH. ${ }^{5}$ These studies suggest that vitreopapillary traction may be part of the natural course of diabetic retinopathy, with either NPDR or PDR. In the current series with vitreopapillary traction, macular detachment was not detected but rather localized detachment of the peripapillary area and/or diffuse DME were found. In contrast, Kaiser et $a l^{15}$ report that taut posterior hyaloid could be associated with diabetic macular detachment.

Recently, we reported on OCT findings of vitreopapillary traction in three eyes (three patients) with CRVO. ${ }^{26}$ In each of the three eyes, secondary peripapillary retinal traction and macular/retinal detachment ('optic disc traction syndrome') developed. It is possible that dense fibrous membranes, which appear following haemorrhage secondary to the CRVO at the $\mathrm{ONH}$ site, retract the $\mathrm{ONH}$ substantially to result in retinal detachment. Furthermore, the marked reduction of vision following CRVO and the often appearing dense fibrous membranes several weeks after the occlusive event could result in a delay in both new patient complaints and/or in diagnoses of the detachment. In contrast, vitreopapillary traction in diabetic eyes seems to be milder, although it can result in $\mathrm{ONH}$ elevation, and possibly in stretching and kinking of ganglion cell axons and the prelaminar blood flow. These could result in an adjacent parapapillary detachment or diffuse oedema and earlier patient complaints.

We were unaware of any previous reports of patients with vitreopapillary traction associated with diffuse DME, and we could find no reference to it in a computerized search using Medline. The OCT is a powerful tool to demonstrate these pathologies. Limitations of the study may be related to the possibility that in some cases with sole vitreopapillary traction, vitreomacular traction was not detected because the current OCT enables the detection of traction bands with thickness up to $10-15 \mu \mathrm{m}$, but not thinner. However, in addition to the importance of early diagnosis of vitreopapillary traction and probable early surgery for the prevention of progressive optic atrophy in some eyes, ${ }^{2}$ further studies should indicate whether diffuse DME, or maybe certain oedema contours such as maximal thickening in proximity to the elevated $\mathrm{ONH}$, could suggest a cause and effect with vitreopapillary traction in these eyes.

\section{References}

1 de Bustros S, Thompson JT, Michels RG, Rice TA. Vitrectomy for progressive proliferative diabetic retinopathy. Arch Ophthalmol 1987; 105: 196-199.

2 Kroll P, Wiegand W, Schmidt J. Vitreopapillary traction in proliferative diabetic retinopathy. Br J Ophthalmol 1999; 83: 261-264.

3 Lam HD, Blumenkranz MS. Treatment of central retinal vein occlusion by vitrectomy with lysis of vitreopapillary and epipapillary adhesions, subretinal peripapillary tissue plasminogen activator injection and photocoagulation. Am J Ophthalmol 2002; 134: 609-611.

4 Katz B, Hoyt WF. Intrapapillary and peripapillary hemorrhage in young patients with incomplete posterior vitreous detachment. Signs of vitreopapillary traction. Ophthalmology 1995; 102: 349-354.

5 Wisotsky BJ, Magat-Gordon CB, Puklin JE. Vitreopapillary traction as a cause of elevated optic nerve head. Am J Ophthalmol 1998; 126: 137-138.

6 Antcliff RJ, Marshall J. The pathogenesis of edema in diabetic maculopathy. Semin Ophthalmol 1999; 14: 223-232.

7 Funatsu H, Yamashita H, Ikeda T, Nakanishi Y, Kitano S, Hori S. Angiotensin II and vascular endothelial growth factor in the vitreous fluid of patients with diabetic macular edema and other retinal disorders. Am J Ophthalmol 2002; 133: 537-543.

8 Funatsu H, Yamashita H, Mona H, Minura T, Yamashita T, Hori S. Increased levels of vascular endothelial growth factor and interleukin-6 in aqueous humor of diabetic with macular edema. Am J Ophthalmol 2002; 133: 70-77.

9 Early Treatment Diabetic Retinopathy Study Report Number 1: photocoagulation for diabetic macular edema. Arch Ophthalmol 1985; 103: 1796-1806.

10 Lee CM, Olk RJ. Modified grid laser photocoagulation for diffuse macular edema: long term results. Ophthalmology 1991; 98: 1594-1602.

11 Jonas JB, Kreissig I, Sofker A, Degenring RF. Intravitreal injection of triamcinolone for diffuse diabetic macular edema. Arch Ophthalmol 2003; 121: 57-61.

12 Martidis A, Duker JS, Greenberg PB, Rogers AH, Puliafito $\mathrm{CA}$, Reichel $\mathrm{E}$ et al. Intravitreal triamcinolone for refractory diabetic macular edema. Ophthalmology 2002; 109: 920-927.

13 Massin P, Duguid G, Erginay A, Haouchine B, Gaudric A. et al. Optical coherence tomography for evaluating diabetic macular edema before and after vitrectomy. Am J Ophthalmol 2003; 135: 169-177.

14 Pendergast SD, Hassan TS, Williams GA, Cox MS, Margherio RR, Ferrone PJ et al. Vitrectomy for diffuse diabetic macular edema associated with a taut premacular posterior hyaloid. Am J Ophthalmol 2000; 130: 178-186.

15 Kaiser PK, Riemann CD, Sears JE, Lewis H. Macular traction detachment and diabetic macular edema associated with posterior hyaloidal traction. Am J Ophthalmol 2001; 131: $44-49$.

16 Ikeda T, Sato K, Katano T, Hayashi Y. Vitrectomy for cystoid macular edema with attached posterior hyaloid membrane in patients with diabetes. Br J Ophthalmol 1999; 83: 12-14.

17 La Heij EC, Hendrikse F, Kessels AG, Derhaag PJ. Vitrectomy results in diabetic macular edema without evident vitreomacular traction. Graefes Arch Clin Exp Ophthalmol 2001; 239: 264-270. 
18 Ikeda T, Sato K, Katano T, Hayashi Y. Improved visual acuity following pars plana vitrectomy for diabetic cystoid macular edema and detached posterior hyaloid. Retina 2000; 20: $220-222$.

19 Swanson EA, Izatt JA, Hee MR, Huang D, Lin CP, Schuman JS et al. Optical coherence tomography. Opt Lett 1993; 18: 1864-1866.

20 Puliafito CA, Hee MR, Schuman JS, Fujimoto JG. Diseases of the optic nerve. In: Optical Coherence Tomography of Ocular Diseases. Slack Inc., New Jersey, 1996; pp: $357-368$

21 Foos RY. Posterior vitreous detachment. Trans Am Acad Ophthalmol Otolaryngol 1972; 76: 480-497.

22 Uchino E, Uemura A, Ohba N. Initial stages of posterior vitreous detachment in healthy eyes of older persons evaluated by optical coherence tomography. Arch Ophthalmol 2001; 119: 1475-1479.

23 Goebel W, Kretzchmar-Gross T. Retinal thickness in diabetic retinopathy: a study using optical coherence tomography (OCT). Retina. 2002; 22: 759-767.

24 Lattanzio R, Brancato R, Pierro L, Bandello F, Iaccher B, Fiore $\mathrm{T}$ et al. Macular thickness measured by optical coherence tomography (OCT) in diabetic patients. Eur J Ophthalmol 2002; 12: 482-487.

25 Pendergast SD, Martin DF, Proia AD, Jaffe GJ, McCuen BW II. Removal of optic disc stalks during diabetic vitrectomy. Retina 1995; 15: 25-28.

26 Rumelt S, Karatas M, Pikkel J, Majlin M, Ophir A. Vitreopapillary traction syndrome associated with central retinal vein occlusion. Arch Ophthalmol 2003; 121: 1093-1097. 